Cultural Heritage

Elsevier Editorial System(tm) for Journal of

Manuscript Draft

Manuscript Number: CULHER-D-15-00230R1

Title: Effects of natural and artificial ageing on the physical and acoustic properties of wood in musical instruments

Article Type: Wooden musical instruments special issue

Keywords: Wood; ageing; musical instrument; hygroscopicity; acoustic property

Corresponding Author: Dr. Eiichi Obataya, Dr

Corresponding Author's Institution: Tsukuba University

First Author: Eiichi Obataya, Dr

Order of Authors: Eiichi Obataya, Dr

Manuscript Region of Origin: JAPAN

Abstract: The reversible and irreversible effects of natural and artificial hydrothermal ageing are reviewed with respect to the hygroscopicity and acoustic properties relevant to the practical quality of wooden musical instruments. Long-term natural ageing reduces the hygroscopicity of wood while improving its acoustic quality, but these changes are partly reversible by exposure to high humidity. Similar reversible changes are observed in hydrothermally treated wood, especially when the wood is heated at an intermediate relative humidity. These reversible changes are attributed to the annealing-like rearrangement of amorphous wood polymers or the temporary closure of micropores, but further investigation is necessary. Color change resulting from natural ageing is shown to be successfully reproducible by oven-heating. 


\title{
Title: Effects of natural and artificial ageing on the physical and acoustic properties of wood in musical instruments
}

\author{
Author: Eiichi Obataya \\ Graduate School of Life and Environmental Sciences \\ Tsukuba University \\ Ibaraki 305-8572, Japan \\ E-mail: obataya.eiichi.fu@u.tsukuba.ac.jp
}

\begin{abstract}
The reversible and irreversible effects of natural and artificial hydrothermal ageing are reviewed with respect to the hygroscopicity and acoustic properties relevant to the practical quality of wooden musical instruments. Long-term natural ageing reduces the hygroscopicity of wood while improving its acoustic quality, but these changes are partly reversible by exposure to high humidity. Similar reversible changes are observed in hydrothermally treated wood, especially when the wood is heated at an intermediate relative humidity. These reversible changes are attributed to the annealing-like rearrangement of amorphous wood polymers or the temporary closure of micropores, but further investigation is necessary. Color change resulting from natural ageing is shown to be successfully reproducible by oven-heating.
\end{abstract}

\section{Research aims}

This article describes the irreversible and reversible effects of both natural and hydrothermal artificial ageing on the properties of wood relevant to the quality of wooden musical instruments. The effects of ageing are usually attributed to irreversible chemical changes in wood polymers, such as the recrystallization of cellulose and depolymerization of hemicelluloses. However, recent investigations suggest that the effects of ageing are partly recoverable by rewetting or moistening in humid conditions. This reversible phenomenon is likely caused by conformational changes during the physical ageing of wood polymers, which should be considered for the appropriate conservation of the properties of old wooden cultural artifacts.

\section{Introduction}

For musicians and artisans dealing with musical instruments made from wood, the ageing process is not considered degradation but a treatment that improves the acoustic quality and stability of wooden instruments. Old lumber is often priced higher than recently cut wood for making the soundboard and bass bar of stringed instruments. According to Noguchi et al., aged pine wood 
shows a higher sound velocity $(V)$ and lower loss tangent $(\tan \delta)$ than newly cut wood, while the rigidity ratios $\left(E^{\prime} / G^{\prime}\right.$ in which $E^{\prime}$ is the dynamic Young's modulus and $G^{\prime}$ is the dynamic shear modulus) of woods of different ages are nearly equal [1]. A higher $V$ and lower $\tan \delta$ increase the amplitude of sound radiation [2,3], and the high $E / G$ ratio of wood creates its characteristic frequency response [4]. Therefore, wooden soundboards become more resonant while maintaining their tone quality with long-term ageing. Moreover, long-term ageing reduces the hygroscopicity of wood in general $[5,6]$. The reduced hygroscopicity improves the dimensional stability of wood, as well as stabilizing its mechanical and acoustic properties depending on the moisture content. Thus, the empirical approach of musicians and artisans to the effects of ageing on the acoustic quality and stability of wood is well-supported by material analysis.

The enhanced rigidity and reduced damping of aged wood have not yet been fully explained. Noguchi et al. have speculated that cellulose crystallization contributes to the higher $E$ value and lower $\tan \delta$ value of aged wood [1], but this hypothesis was later negated: no significant difference was recognized in the crystallinity of new and aged wood samples [7]. Yokoyama et al. also found equivalent degrees of crystallinity between new and aged woods [6]. According to Inagaki et al., the degree of crystallinity increases by both ageing and hydrothermal treatments which cause the decomposition of the amorphous regions in cellulose and hemicelluloses; however, the increase of crystallite thickness was confirmed only for hydrothermally treated wood [8]. From these results, the crystallization of cellulose can be concluded to be a minor mechanism for the enhancing effects of ageing. Other possible mechanisms include hornification [9], the cross-linking reaction in lignin, and the rearrangement of disordered polysaccharides, but those hypotheses require further experimentation.

Meanwhile, the improved stability or reduced hygroscopicity of aged wood is fully explained by the decomposition of hemicelluloses, which is the most significant chemical change in wood during ageing $[10,11]$. As hemicelluloses are the most hygroscopic components of wood, their decomposition reduces the hygroscopicity. The decomposition of hemicelluloses also reduces the ductility and toughness of wood; these amorphous polysaccharides are crucial to the tight connections between reinforcing cellulose microfibrils and amorphous matrix polymers [12-14]. In fact, the tensile strength [15], rupture energy in bending [6], impact bending strength [5, 16], and cleavage resistance [5] are all significantly reduced by ageing. These adverse effects of ageing are qualitatively similar to those induced by hydrothermal treatment, which involves the remarkable hydrolysis of hemicelluloses [18]. The fragile nature of aged wood must be considered when wooden parts of musical instruments are loaded with strong forces, such as the tension of strings. In general, the effects of ageing are most frequently explained as results of irreversible changes, such as the decomposition of hemicelluloses. However, recent investigations have suggested that 
the effects of both natural and artificial hydrothermal ageing can be partly reversed by moistening or rewetting the wood sample [18-20]. These reports imply that the wood ageing process involves some recoverable, i.e., reversible changes in the wood cell wall. The reversible effect of ageing may be related to the effects of seasoning and playing, which must be considered for the appropriate conditioning of old wooden instruments. In this paper, the reversible and irreversible effects of natural and artificial ageing on the physical properties of wood are described. In addition, some recent studies on the color of aged wood are briefly discussed regarding the restoration and imitation of the physical appearance of old wooden musical instruments.

\section{The effects of natural ageing}

\subsection{Change in hygroscopicity}

The hygroscopicity of wood sample can be evaluated by the equilibrium moisture content (EMC) at a constant relative humidity (RH). In general, the EMC of wood at an intermediate RH $(60-65 \%)$ remains unchanged [15] or decreases during long-term ageing [5, 6]. Some aged wood shows higher hygroscopicity than new wood [21], but in these cases, the aged wood is similar to submersed (water-logged) wood in terms of moisture sorption characteristics [22]. As submersed lumber is rarely used for musical instruments, these cases are irrelevant to this paper.

The reduced hygroscopicity of aged wood is usually attributed to the decomposition and loss of hygroscopic hemicelluloses. This explanation holds if the effects of ageing are always irreversible. However, the reduced hygroscopicity of aged wood was recently found to be recoverable by a moistening treatment. Figure 1 shows the relative EMC of aged wood before and after the moistening treatment [19]. In Fig.1, the EMC values of aged wood are normalized relative to those of recently cut wood under the same conditions. The EMC values of aged wood are always lower than those of recently cut wood, but with moistening at $100 \%$ RH for several days, its EMC values are at least partially recovered, especially at low RH. Notably, the different trends in Fig.1 do not reflect sorption hysteresis, because these EMC values are always determined in the adsorption process. Thus, the effect of ageing is partly reversible with respect to hygroscopicity.

A possible interpretation for the cause of the temporary reduction in hygroscopicity by ageing is the physical ageing or annealing of wood polymers. Figures 2 and 3 schematically illustrate the fine structure of wood cell wall and the mechanism of internal stress during drying, respectively. The wood cell wall is a composite in which crystalline cellulose fibers are embedded in amorphous matrix substances. The crystalline cellulose is rigid and hydrophobic, whereas the amorphous matrix polymers are swollen with moisture in green state and ready to shrink by drying. As wood dries from its green state (Fig.3A), the shrinkage of amorphous wood polymers is restricted by the adjacent crystalline cellulose. Therefore, the amorphous polymers are distorted 
and dry under applied stress, as in the quenching of synthetic polymers (Fig.3B). Since the amorphous wood polymers are glassy and immobile in dry conditions, the drying stress cannot immediately be relaxed. During long-term ageing, however, it may gradually relax (Fig.3E) and such an annealing-like rearrangement of wood polymers reduces the hygroscopicity of the wood. On the other hand, the wood polymers recover their initial arrangements once they are re-swollen and plasticized by moisture at high RH (Fig.3G). Therefore, the hygroscopicity is recovered by moistening and subsequent drying. This hypothesis was originally proposed to explain the temporary reduction in hygroscopicity resulting from oven heating [23], but can be applied to the present case in which the natural ageing process can be regarded as a long-term hydrothermal treatment at ambient temperature. The annealing effect may also account for the reduction in hygroscopicity caused by repeated humidity cycling [24]. Although it is technically difficult to observe the slight conformational changes in amorphous wood polymers, X-ray diffractometry may give useful information about the distortion of amorphous wood polymers, as it can detect the deformation of cellulose crystals accompanied by the shrinkage and swelling of amorphous wood polymers [25].

Another potential mechanism underlying the temporary reduction in hygroscopicity by ageing is the closure of micropores. Kojiro et al. [18] have determined the presence of micropores smaller than $0.6 \mathrm{~nm}$ in new and aged cypress wood $(0.1-1000 \mathrm{y})$ by $\mathrm{CO}_{2}$ adsorption measurements. The micropores decreased in number with ageing, but increased after rewetting and drying. This coincides with the temporary reduction in EMC from ageing and its recovery by moistening, particularly at a low RH (Fig.1). The temporary closure of micropores is possibly responsible for the enhanced rigidity of aged wood, as well as the reduction in hygroscopicity by repeated humidity cycling [24].

As shown in Fig.1, the EMC values of aged wood remain lower than those of new wood at a higher RH, whereas at a low RH they become closer to those of new wood after the moisture recovery treatment. This trend is similar to that observed in oven-heated wood, whereas steamed wood shows a reverse trend [26]. The greater reduction in EMC at a higher RH is also observed in formaldehyde-treated wood [27] in which the swelling of wood is restricted by the tight covalent bonds formed between the amorphous wood polymers. These facts imply that the irreversible effects of ageing result from cross-linking or similar structural changes that restrict the swelling of wood, rather than a decreasing number of active adsorption sites.

\subsection{Changes in vibrational properties}

In general, a higher specific dynamic Young's modulus $(E \% \rho)$, higher sound velocity $(V)$, and lower mechanical loss tangent $(\tan \delta)$ are desired for the soundboards of musical instruments [2-4, 
25]. These vibrational properties depend not on the density and wood species, but on the microfibril angles in the cell wall [26, 27]. In some species, $\tan \delta$ is considerably reduced [28] or enhanced [29] in the presence of water-soluble extractives, but the particular effects of these extractives are not detailed here.

Noguchi et al. have found that long-term ageing improves the acoustic quality of red pine wood [1]. This coincides with the empirical knowledge of musicians and artisans. However, recently, Maejima et al. have found that the vibrational properties of aged wood are influenced by moistening [19]. Figure 4 shows the relative $E \% \rho$ and $\tan \delta$ values of aged wood at $25^{\circ} \mathrm{C}$ and $60 \%$ $\mathrm{RH}$ as a function of EMC. The EMC in the desorption process is higher than that in the adsorption process because of the moisture sorption hysteresis. In addition, moistening affects the EMC of aged wood, as described above. Notably, $E \% \rho$ decreases and $\tan \delta$ increases after moistening at $100 \%$ RH. This indicates the temporary effects of enhanced $E \% \rho$ and reduced $\tan \delta$ by ageing; however, these temporary effects are reset by the moistening process. The temporary effects must be closely related to the annealing of wood polymers and closure of micropores, but a convincing mechanism for this relationship has not yet been reported.

The temporary and recoverable effects of ageing must be considered when we wish to maintain the acoustic quality of old wooden instruments. Once an old instrument is exposed to highly humid conditions, the temporary effects of ageing will disappear and the ageing-improved quality of the instrument may degrade.

\section{Artificial ageing of wood}

Hydrothermal treatment is an ecologically friendly method to improve the practical performance of wood. The dimensional stability, durability, and mechanical properties of wood are generally improved when the wood is heated in air, oil, or water vapor at temperatures higher than $100^{\circ} \mathrm{C}$. Recent investigations on the hydrothermal treatment of wood and its potential applications were reviewed by Sandberg et al. [17].

The hydrothermal treatment is sometimes referred to as artificial or accelerated ageing, because the chemical reactions involved in natural ageing are accelerated by the elevated temperature. Strictly speaking, however, the claim of accelerated ageing has little basis in reality, because the ageing of wood involves many different chemical reactions following different reaction kinetics. Chédeville and co-researchers have confirmed that ultraviolet resonance Raman spectra of artificially aged wood were dissimilar to those of naturally aged wood when the wood was heated to $160^{\circ} \mathrm{C}$ or above [33]. This suggests that the properties of naturally aged wood are not easily reproduced by the hydrothermal treatment of new wood. However, particular properties of aged wood, such as enhanced rigidity, reduced hygroscopicity, and darkened color, can be successfully 
reproduced by appropriate hydrothermal treatment. In this section, the effects of hydrothermal treatment on the hygroscopicity, vibrational properties, and color of wood are described, summarizing its potential for the imitation of naturally aged wood.

\subsection{Reduction in hygroscopicity}

In general, hydrothermal treatment is conducted in dry air $(0 \% \mathrm{RH})$ or in saturated water vapor (100\% RH); these extreme conditions are easily produced by using an oven and autoclave, respectively. Oven-heating in dry air reduces the EMC of wood, and the reduction in the EMC is greater at a higher RH. Steam-heating the wood, meanwhile, reduces the EMC to a greater degree at a lower RH [26]. These inverse trends suggest that the effects of oven-heating and steaming are qualitatively different, and that the heating relative humidity $(\mathrm{HRH})$ is important in determining the moisture sorption characteristics of hydrothermally treated wood. Recently Borrega and Kärenlampi [34] found that the largest reduction in EMC (at $19^{\circ} \mathrm{C}$ and $65 \% \mathrm{RH}$ ) was achieved by heating at an intermediate HRH (50\%). They speculated that irreversible hydrogen bonding, so-called hornification, was responsible for the particular effect of hydrothermal treatment at an intermediate HRH. However, Endo et al. found more recently that the reduced hygroscopicity of hydrothermally treated wood was considerably recovered by moistening, especially when the wood was heated at an intermediate HRH [20]. Figure 5 shows the effects of HRH on the EMC values of hydrothermally treated wood at $25^{\circ} \mathrm{C}$ and $60 \% \mathrm{RH}$. The EMC is minimized by heating at an intermediate HRH (40-80\%), but once the hydrothermally treated wood is moistened under highly humid conditions, its EMC recovers significantly, showing a monotonic decrease with an increasing HRH. The recovery in EMC cannot be attributed to moisture sorption hysteresis because the EMC values are always determined in the adsorption process: the moistened samples were completely dried in vacuo and then conditioned at $25^{\circ} \mathrm{C}$ and $60 \% \mathrm{RH}$ for a few months before determining their EMC values.

Figure 6 shows the effects of WL on the EMC of hydrothermally treated wood both before and after the moistening treatment. As suggested by Borrega and Kärenlampi, the EMC is effectively reduced by heating at an intermediate (29-64\%) HRH (Fig.6a), but this particular effect disappears after the moistening treatment (Fig.6b). These results indicate the temporary reduction of the EMC of wood by hydrothermal treatment, particularly when the wood is heated at an intermediate HRH. The temporary effect of hydrothermal treatment presumably results from the annealing or physical ageing of wood polymers as observed during the natural ageing of wood. When wood is heated at a low HRH, the thermal activation of the wood polymers allows their rearrangement accompanied by the relaxation of the drying stress, as mentioned above. Such an annealing effect is maximized at an intermediate HRH because a certain amount of moisture can act as a plasticizer, easing the 
rearrangement of wood polymers. At a higher $\mathrm{HRH}$, the annealing effect (or temporary reduction in EMC) decreases because less initial drying stress exists to be relaxed. Meanwhile, the irreversible effects monotonically increase with an increasing $\mathrm{HRH}$, because the decomposition of wood polymers such as the hydrolysis of hemicelluloses is accelerated in the presence of moisture. The temporary and reversible effects of hydrothermal treatment have not been considered in many cases. When we evaluate the hygroscopicity of hydrothermally treated wood, the irreversible effect should be clearly distinguished from the reversible effect; otherwise, we may overestimate the practical performance of the treatment regarding metrics such as dimensional stability.

Additionally, the reversible effect should be considered when hydrothermally treated woods are used to imitate and restore the properties of old cultural artifacts, because the dimensional and moisture-dependent mechanical properties may irreversibly change after exposure to high humidity, as would occur in the rainy season.

\subsection{Changes in vibrational properties}

Many investigations have been made on the mechanical properties of hydrothermally treated or kiln-dried wood for reasons of practical importance [17]. In general, the mechanical properties of hydrothermally treated wood are well correlated with the WL, irrespective of heating temperature. With increasing WL, the bending Young's modulus $(E)$ of wood increases slightly and then decreases whereas its bending strength and toughness decrease monotonically [35-38]. The $E$ ' $\rho$ values are also enhanced by both dry heating [39] and steaming [40]. These enhancing effects have usually been attributed to the recrystallization of cellulose, while the reduced strength and ductility are attributed to the decomposition of hemicelluloses [39, 41].

Meanwhile, little information is available regarding the $\tan \delta$ of hydrothermally treated wood. According to Kubojima et al., the $\tan \delta$ of spruce wood in the direction parallel to its fibers increases by heating the wood at $160^{\circ} \mathrm{C}$ for several hours in dry nitrogen gas, whereas that of green spruce wood slightly decreases when heated in an autoclave at high HRH [40]. These changes in $\tan \delta$ may reflect different structural changes in the wood polymers, such as the cross-linking reaction in lignin [42, 43] and the recrystallization of cellulose [39, 41]. By heating at higher temperatures or for longer durations, the $\tan \delta$ increases to a remarkable degree, probably because of the depolymerization of hemicelluloses. These results imply that relatively mild heating may enhance the acoustic quality of wooden soundboards.

Few attempts have been made on investigating the effects of heating at an intermediate HRH, and little attention has been paid to the reversible effects of the hydrothermal treatment. Endo et al. recently reported a precise measurement of the $E \% \rho$ and $\tan \delta$ of spruce wood, before and after hydrothermal treatment at $120^{\circ} \mathrm{C}$ and various $\mathrm{HRH}(0-95 \%)$ for 1-7 days [20]. Figure 7 shows the 
changes in $E \% \rho$ and $\tan \delta$ values of Sitka spruce wood with hydrothermal treatment at 57-64\% HRH. With heating at an intermediate HRH, the $E \% \rho$ increased and the $\tan \delta$ decreased. These results indicate that the acoustic qualities of wood can be improved by heating at an intermediate HRH. However, the effects of hydrothermal treatment are, importantly, recoverable and not permanent. In fact, the vibrational properties of hydrothermally treated wood approach those of unmodified wood after a moistening treatment, as shown in Fig.7. That is, the effects of hydrothermal treatment could be easily overestimated unless the wood is tested after sufficient moistening.

Figure 8 shows the irreversible effects of hydrothermal treatment on the $E$ ' $/ \rho$ and $\tan \delta$ values of spruce wood. When wood is heated at a high HRH (89-95\%), the E' $\rho$ decreases remarkably and $\tan \delta$ increases steeply with increasing WL. At $0 \%$ HRH, the $E \% \rho$ and $\tan \delta$ remain almost unchanged, because the thermal degradation proceeds very slowly in the absence of moisture. In contrast, a slight but significant increase in $E^{\prime} / \rho$ and decrease in $\tan \delta$ are observed when the wood is heated at an intermediate (29-82\%) HRH. This suggests that hydrothermal treatment may improve the acoustic quality of wooden soundboards, and that appropriate humidity control is necessary for effective modification with minimal degradation. Further investigations are necessary to clarify the effects of HRH at different heating temperatures, which will allow time-temperature-humidity conversions in the hydrothermal treatment of wood.

\subsection{Changes in color}

The color of wood darkens gradually with long-term ageing, even when the wood is carefully conserved indoors, kept dry, protected from sunlight, and prevented from biological attacks. The color of wood is especially important for the imitation and restoration of old wooden instruments. According to Matsuo et al. [44-46], the darkened color of aged wood can be precisely reproduced by oven-heating, because the time-temperature superposition principle is applicable to the color changes. Thus, the oven-heating of wood is a useful method for the restoration and imitation of the visual properties of old wooden artifacts.

\section{Effects of forced vibration (playing effect)}

Many musicians believe that the quality of instrument is improved by continuous playing; however, sensory evaluation tests indicate that playing has no significant effect on the tone quality of guitars and violins $[47,48]$. Continuous vibration, on the other hand, has been reported several times to affect the vibrational properties of wood. Sobue and Okayasu found that the $\tan \delta$ of wood decreased exponentially with time under forced vibration, whereas the $E$ ' remained unchanged, irrespective of wood species [49]. A similar phenomenon was reported by Hunt and Balsan [50]. 
Sobue and Okayasu hypothesized that the $\tan \delta$ of wood polymers was increased by the drying stress remaining in the wood cell wall, and that continuous vibrations may have stimulated the relaxation of the drying stress, thus reducing the $\tan \delta$ of wood. This speculation seems reasonable, because continuous vibration only slightly affected the $\tan \delta$ of spruce wood at $100 \% \mathrm{RH}$, in which only a small amount of drying stress remained in the wood cell wall [51]. If the relaxation of drying stress is a major mechanism underlying the so-called playing effect, the changes in properties induced by the playing effect may be recovered by moistening and subsequent drying. Therefore, it is advisable to conserve wooden musical instruments in dry conditions, because the improved acoustic performance may degrade when the wood is exposed to humid conditions.

\section{Conclusions}

The reversible and irreversible effects of natural and artificial ageing are discussed, with respect to the hygroscopicity and acoustic properties relevant to the practical quality of wooden musical instruments. Long-term natural ageing affects the hygroscopicity and acoustic properties of wood, but the effects of ageing are at least partially recovered by moistening the wood under highly humid conditions. Similar reversibility is observed in hydrothermally treated wood, especially when the wood is heated at an intermediate relative humidity. The physical or annealing-like rearrangement of amorphous wood polymers and/or the temporary closure of micropores are hypothesized as mechanisms underlying the reversible changes in wood properties; further investigations are necessary to test these hypotheses.

\section{Acknowledgements}

The author appreciates Ms. Kaoru Endo and Mr. Shuoye Chen for their permission to reproduce their presentation. The author is also grateful to Dr. Miyuki Matsuo and Dr. Marc Borrega for providing useful information about the hydrothermal treatment of wood.

\section{References}

[1] T. Noguchi, E. Obataya, K. Ando, Effects of aging on the vibrational properties of wood, J. Cultural Heritage 13S (2012) S21-S25.

[2] H. Yano, H. Matsuhisa, Study on the timber of wood II, analysis of the sound spectrum of wood using viscoelastic Timoshenko equation, Sci. Rep. Kyoto Prefectural Univ. 43 (1991) 24-31. [3] T. Ono, Frequency responses of wood for musical instruments in relation to the vibrational properties, J. Acoust. Soc. Jpn. (E) 17 (1996) 183-193.

[4] T. Ono, Transient response of wood for musical instruments and its mechanism in vibrational property, J. Acoust. Soc. Jpn. (E) 20 (1999) 117-124. 
[5] J. Kohara, Studies on the permanence of wood VI, the changes of mechanical properties of old timbers (in Japanese), Bull. Kyoto Prefectural Univ. 6 (1954) 164-174.

[6] M. Yokoyama, J. Gril, M. Matsuo, H. Yano, J. Sugiyama, B. Clair, S. Kubodera, T. Mitsutani, M. Sakamoto, H. Ozaki, M. Imamura, S. Kawai, Mechanical characteristics of aged Hinoki wood from Japanese historical buildings, Comp. Rend. Phys. 10 (2009) 601-611.

[7] T. Noguchi, E. Obataya, K. Ando, H. Yamamoto, Y. Ogawa, M. Wada, Vibrational properties of aged pine wood (Pinus densiflora), Abstracts of the 62th Annual Meeting of the Japanese Wood Research Society (2012), C16-04-1515.

[8] T. Inagaki, H. W. Siesler, K. Mitsui, S. Tsuchikawa, Difference of the crystal structure of cellulose in wood after hydrothermal and aging degradation: A NIR spectroscopy and XRD study, Biomacromolecules 11 (2010), 2300-2305.

[9] K. L. Kato, R. E. Cameron, Structure-property relationships in thermally aged cellulose fibers and paper, J. Appl. Polym. Sci. 74 (1999), 1465-1477.

[10] J. Kohara, Studies on the permanence of wood VII, the influence of age on the components of wood (Chamaecyparis obtusa Endl.) (in Japanese), Bull. Kyoto Prefectural Univ. 6 (1954)

175-182.

[11] R. Widyorini, M. Yokoyama, J. Sugiyama, S. Kawai, T. Mitsutani, S. Kubodera, M. Ozaki, M. Sakamoto, M. Imamura, Evaluation of aged wood from historical Japanese buildings II - Changes in chemical component, Abstracts of the 57th Annual Meeting of the Japanese Wood Research Society (2007) C09-1015.

[12] M. Åkerholm, L. Salmén, Interactions between wood polymers studied by dynamic FT-IR spectroscopy, Polymer 42 (2001), 963-969.

[13] K. Abe, H. Yamamoto, Change in mechanical interaction between cellulose microfibril and matrix substance in wood cell wall induced by hygrothermal treatment. J Wood Sci 52 (2006), 107-110.

[14] R. Kaida, E. Obataya, M. Yoshida, F. Ishiguri, J. Tanabe, T. Taniguchi, M. Kurita, K. Baba, T. Hayashi, Occurrence of xyloglucan in the xylem of poplar stems for wind and earthquake, Abstracts of the International Symposium on Wood Science and Technology, Tokyo, Japan (2015), 5FS-O04.

[15] Y. Hirashima, M. Sugihara, Y. Sasaki, K. Ando, M. Yamasaki, Strength properties of aged wood I, tensile strength properties of aged Keyaki and Akamatsu woods (in Japanese), Mokuzai Gakkaishi 50 (2004) 301-309.

[16] Y. Hirashima, M. Sugihara, Y. Sasaki, K. Ando, M. Yamasaki, Strength properties of aged wood III, static and impact bending strength properties of aged Keyaki and Akamatsu woods (in Japanese), Mokuzai Gakkaishi 51 (2005) 146-152. 
[17] D. Sandberg, P. Haller, P. Navi, Thermo-hydro and thermo-hydro-mechanical wood processing: An opportunity for future environmentally friendly wood products, Wood Mat.Sci.Eng. 8 (2013) 64-88.

[18] K. Kojiro, Y. Furuta, M. Ohkoshi, Y. Ishimaru, M. Yokoyama, J. Sugiyama, S. Kawai, T. Mitsutani, H. Ozaki, M. Sakamoto, M. Imamura, Changes in micropores in dry wood with elapsed time in the environment. J. Wood Sci. 54 (2008), 515-519.

[19] H. Maejima, K. Endo, E. Obataya, Effects of moistening treatment on the hygroscopicity and vibrational properties of aged wood, Abstracts of the International Symposium on Wood Science and Technology, Tokyo, Japan (2015), 1WP-P01.

[20] K. Endo, H. Maejima, E. Obataya, Hygroscopicity and vibrational properties of hydrothermally-treated wood, Abstracts of the International Symposium on Wood Science and Technology, Tokyo, Japan (2015), 1WP-P05.

[21] L. G. Esteban, F. G. Fernández, A, G. Casasús, P. Palacios, J. Gril, Comparison of the hygroscopic behaviour of 205-year-old and recently cut juvenile wood from Pinus sylvestris L, Ann. For. Sci. 63 (2006) 309- 317

[22] L. G. Esteban, P. Palacios, F. G. Fernández, A. Guindeo, M. Conde, V. Baonza, Sorption and thermodynamic properties of juvenile Pinus sylvestris L. wood after 103 years of submersion, Holzforschung 62 (2008), 745-751.

[23] E. Obataya, B. Tomita, Hygroscopicity of heat-treated wood II. Reversible and irreversible reductions in the hygroscopicity of wood due to heating (in Japanese), Mokuzai Gakkaishi 48 (2002) 288-295.

[24] L. G. Esteban, J. Gril, P. D. Palacios, A. G. Casasús, Reduction of wood hygroscopicity and associated dimensional response by repeated humidity cycles. Ann. For. Sci. 62 (2005), 275-284. [25] K. Abe, H. Yamamoto, Mechanical interaction between cellulose microfibril and matrix substance in wood cell wall determined by X-ray diffraction. J Wood Sci 51 (2005), 334-338. [26] E. Obataya, T. Higashihara, B. Tomita, Hygroscopicity of heat-treated wood III, Effects of steaming on the hygroscopicity of wood (in Japanese), Mokuzai Gakkaishi 48 (2002) 348-355. [27] R. Yasuda, K. Minato, M. Norimoto, Moisture adsorption thermodynamics of chemically modified wood, Holzforschung 49 (1995), 548-554.

[28] M. Norimoto, Structure and properties of wood used for musical instruments I, on the selection of wood used for piano soundboards (in Japanese), Mokuzai Gakkaishi 28 (1982), 407413.

[29] E. Obataya, T. Ono, M. Norimoto, Vibrational properties of wood along the grain, J. Materials Sci. 35 (2000) 2993-3001, 6317.

[30] R. Hori, M. Müller, U. Watanabe, H. C. Lichtenegger, P. Fratzl, J. Sugiyama, The importance 
of seasonal differences in the cellulose microfibril angle in softwoods in determining acoustic properties, J. Materials Sci. 37 (2002) 4279 - 4284.

[31] M. Matsunaga, M. Sugiyama, K. Minato, M. Norimoto, Physical and mechanical properties required for violin bow materials, Holzforschung 50 (1996), 511-517.

[32] E. Obataya, M. Norimoto, Acoustic properties of a reed (Arundo donax L.) used for the vibrating plate of a clarinet, J. Acoust. Soc. Am. 106 (1999), 1106-1110.

[33] C. G. Chédeville, A. S. Jääskeläinen, J. Froidevaux, M. Hughes, P. Navi, Natural and artificial ageing of spruce wood as observed by FTIR-ATR and UVRR spectroscopy. Holzforschung 66 (2012), 163-170.

[34] M. Borrega, P. Kärenlampi, Hygroscopicity of heat-treated spruce wood, Proceedings of the Nordic Workshop in Wood Engineering, Skellefteå, Sweden (2007).

[35] M. A. Millett, C. C. Gerhards, Accelerated aging: Residual weight and flexural properties of wood heated in air at $115^{\circ}$ to $175^{\circ} \mathrm{C}$, Wood Science 4 (1972), 193-201.

[36] E.Obataya, S.Shibutani, K.Hanata, S.Doi, Effects of high temperature kiln drying on the practical performances of Japanese cedar wood (Cryptomeria japonica D. Don) II : changes in mechanical properties due to heating, J.Wood Sci. 52 (2006), 111-114.

[37] M. Borrega, P. Kärenlampi, Mechanical behavior of heat-treated spruce (Picea abies) wood at constant moisture content and ambient humidity, Holz Roh Werkst 66 (2008), 63-69.

[38] Y. Kubojima, T. Okano, M. Ohta, Bending strength and toughness of heat-treated wood, J. Wood Sci. 46 (2000), 8-15.

[39] Y. Kubojima, T. Okano, M. Ohta, Vibrational properties of sitka spruce heat-treated in nitrogen gas, J. Wood Sci. 44 (1998), 73-77.

[40] Y. Kubojima, T. Okano, M. Ohta, Vibrational properties of heat-treated green wood, J. Wood Sci. 46 (2000), 63-67.

[41] M. T. R. Bhuiyan, N. Hirai, N. Sobue, Changes of crystallinity in wood cellulose by heat treatment under dried and moist conditions, J. Wood Sci. 46 (2000) 431-436.

[42] B. F. Tjeerdsma, H. Militz, Chemical changes in hydrothermal treated wood: FTIR analysis of combined hydrothermal and dry heat-treated wood, Holz als Roh- und Werkstoff 63 (2005), $102-111$.

[43] H. Wikberg, S. L. Maunu, Characterisation of thermally modified hard- and softwoods by ${ }^{13} \mathrm{C}$ CPMAS NMR, Carbohydrate Polymers 58 (2004), 461-466.

[44] M. Matsuo, M. Yokoyama, K. Umemura, J. Gril, K. Yano, S. Kawai, Color changes in wood during heating: Kinetic analysis by applying a time-temperature superposition method, Appl. Phys. A 99 (2010), 47-52.

[45] M. Matsuo, M. Yokoyama, K. Umemura, J. Sugiyama, S. Kawai, J. Gril, S. Kubodera, T. 
Mitsutani, H. Ozaki, M. Sakamoto, M. Imamura, Ageing of wood: Analysis of color changes during natural aging and heat treatment, Holzforschung 65 (2011), 361-368.

[46] M. Matsuo, E. Karami, S. Bardet, J. Gril, J. Froidevaux, P. Navi, Modelling of the changes in wood properties during hygro-thermal treatment, Abstracts of the 63th Annual Meeting of the Japanese Wood Research Society (2013), X27-06-1645.

[47] B. M. Clemens, J. Kadis, D. M. Clemens, E. Pollak, P. Clark, J. R. Groves, Effect of vibration treatment on guitar tone: a comparative study, Savart J. (September 2014), 1-9.

[48] Ra Inta, J. Smith, J. Wolfe, Measurement of the effect on violins of ageing and playing, Acoustics Australia 33 (2005), 25-29.

[49] N. Sobue, S. Okayasu, Effects of continuous vibration on dynamic viscoelasticity of wood (in Japanese), J. Soc. Mat. Sci. Jpn. 41 (1992), 164-169.

[50] D. G. Hunt, E. Balsan, Why old fiddles sound sweeter, Nature 379 (1996), 681.

[51] H. Akahoshi, S. Chen, E. Obataya, Effects of continuous vibration on the dynamic viscoelastic properties of wood, Annual Conference of COST FP1302 WoodMusiCK, London, UK (2015). 
Captions for figures

Figure 1 Relative equilibrium moisture content (EMC) values of aged red pine wood (279 y after cutting) as a function of relative humidity (RH) [19].

Open plots: aged wood as received; filled plots: aged wood previously moistened at $25^{\circ} \mathrm{C}$ and $100 \% \mathrm{RH}$ for several weeks. All EMC values were determined in the adsorption process.

Figure 2 Multi-layered structure of the wood cell wall (A) and fiber-matrix structure of each layer (B).

Figure 3 A viscoelastic model to explain the drying stress and its relaxation due to ageing and hydrothermal treatment.

a, Viscoelastic matrix; b, adsorbed water; c, elastic crystalline part.

Figure $4 E \%$ and $\tan \delta$ of aged red pine wood ( $279 \mathrm{y}$ after cutting) at $25^{\circ} \mathrm{C}$ and $60 \%$ RH plotted against the EMC [19].

Filled circles: aged wood as received; open triangles: desorption process after moistening treatment at $25^{\circ} \mathrm{C}$ and $100 \% \mathrm{RH}$; open squares: adsorption process after the moistening treatment and subsequent drying in vacuo. The $E \% \rho$ and $\tan \delta$ values are normalized against those determined before the moistening treatment. Each plot indicates the average value of 23 wood specimens.

Broken lines indicate the estimated values based on the moisture dependence of unmodified wood.

Figure 5 Effects of heating relative humidity $(\mathrm{HRH})$ on the EMC of hydrothermally treated Sitka spruce wood at $25^{\circ} \mathrm{C}$ and $60 \% \mathrm{RH}[20]$.

Open plots: hydrothermally treated at $120^{\circ} \mathrm{C}$ for 1 day; filled plots: hydrothermally treated at $120^{\circ} \mathrm{C}$ for 1 day and then moistened at $25^{\circ} \mathrm{C}$ and $100 \% \mathrm{RH}$. All EMC values were determined in the adsorption process.

Figure 6 EMC values of hydrothermally treated Sitka spruce wood at $25^{\circ} \mathrm{C}$ and $60 \% \mathrm{RH}$ plotted against WL before (a) and after (b) the moistening treatment at $25^{\circ} \mathrm{C}$ and $100 \% \mathrm{RH}$ [20]. Crosses: unmodified; open circles: heated at 0\% HRH (heated dry); filled circles: heated at 29-39\% HRH; filled triangles: heated at 57-64\% HRH; filled squares: heated at 77-82\% HRH; open squares: heated at $89-95 \%$ HRH (steamed). Wood specimens were hydrothermally treated in an autoclave at $120^{\circ} \mathrm{C}$ for 1-7 days. All EMC values were determined in the adsorption process. 
Figure 7 Changes in $E \% \rho$ and $\tan \delta$ of spruce wood by hydrothermal treatments at $120^{\circ} \mathrm{C}$ and $57-64 \% \mathrm{HRH}$ as a function of heating duration [20].

Open symbols: hydrothermally treated; filled symbols: hydrothermally treated and moistened; circles: changes in $E^{\prime} / \rho$; squares: changes in $\tan \delta$.

Figure 8 Changes in $E \% \rho$ and $\tan \delta$ of spruce wood at $25^{\circ} \mathrm{C}$ and $60 \%$ RH due to hydrothermal treatment at $120^{\circ} \mathrm{C}$ for $1-7$ days [20].

Open circles: heated at 0\% HRH (heated dry); filled circles: heated at 29-39\% HRH; filled triangles: heated at 57-64\% HRH; filled squares: heated at 77-82\% HRH; open squares: heated at $89-95 \%$ HRH (steamed). The $E \% \rho$ and $\tan \delta$ values of hydrothermally treated wood are normalized by those determined in an unmodified state. 


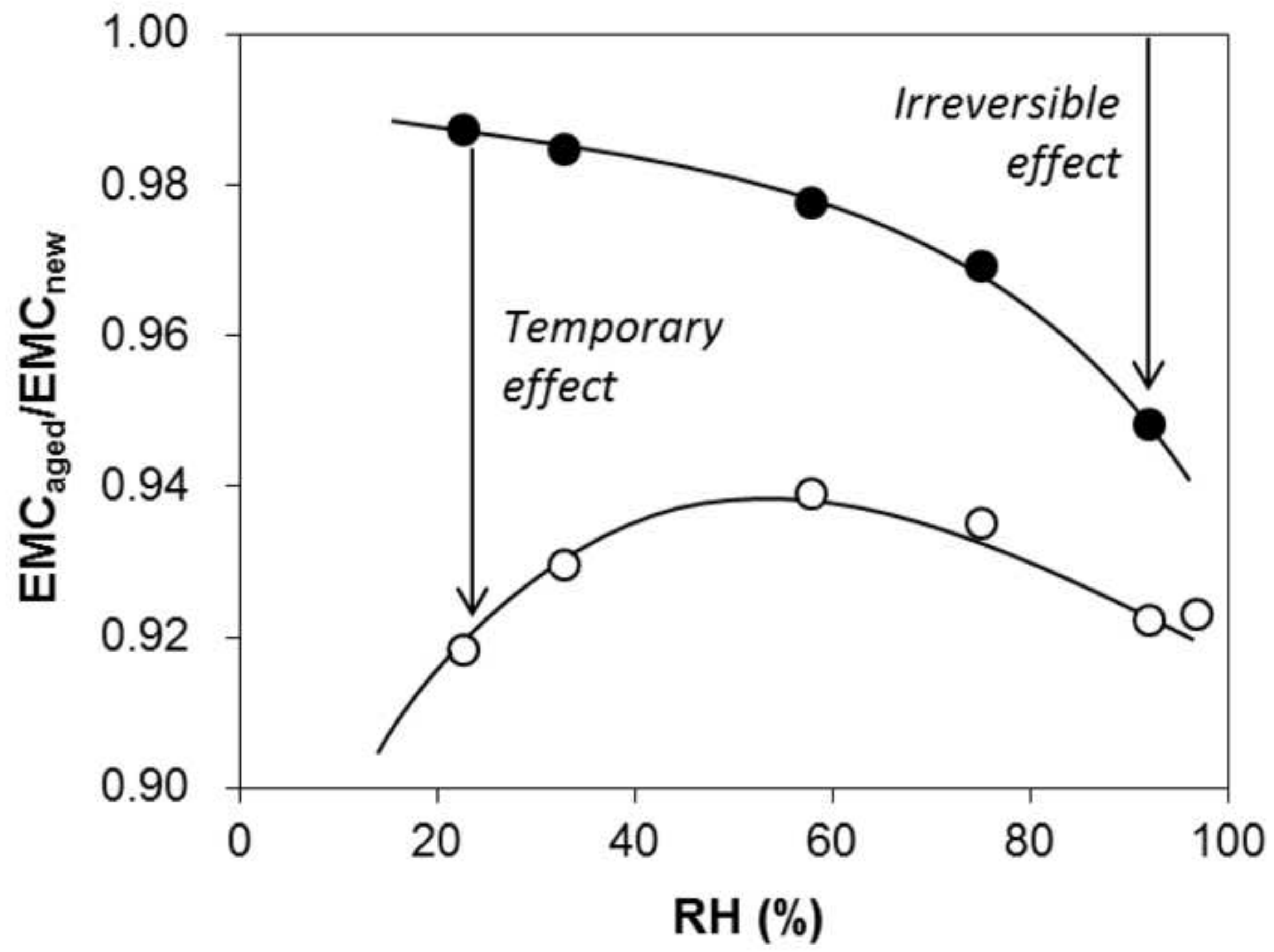


A

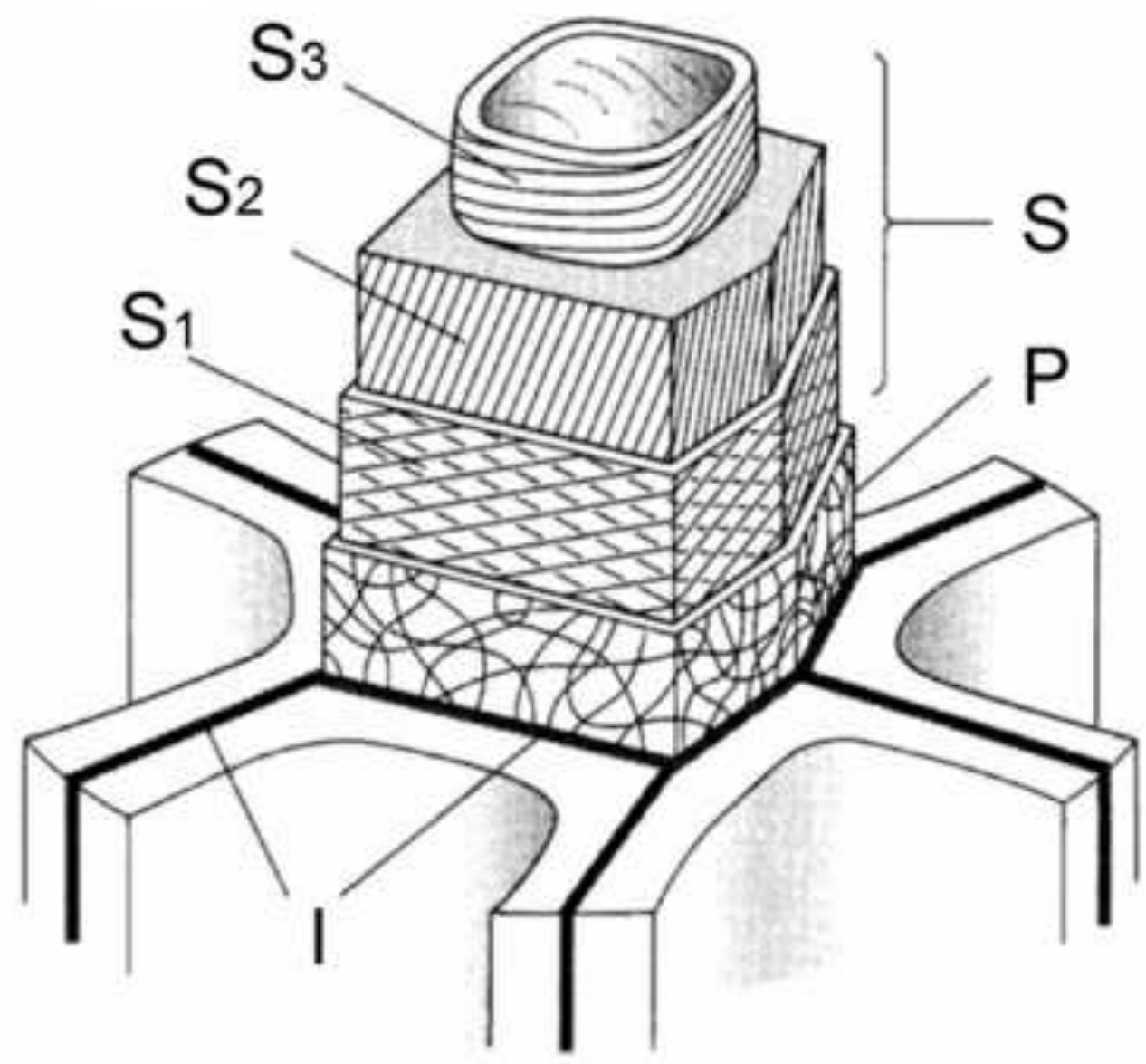

B

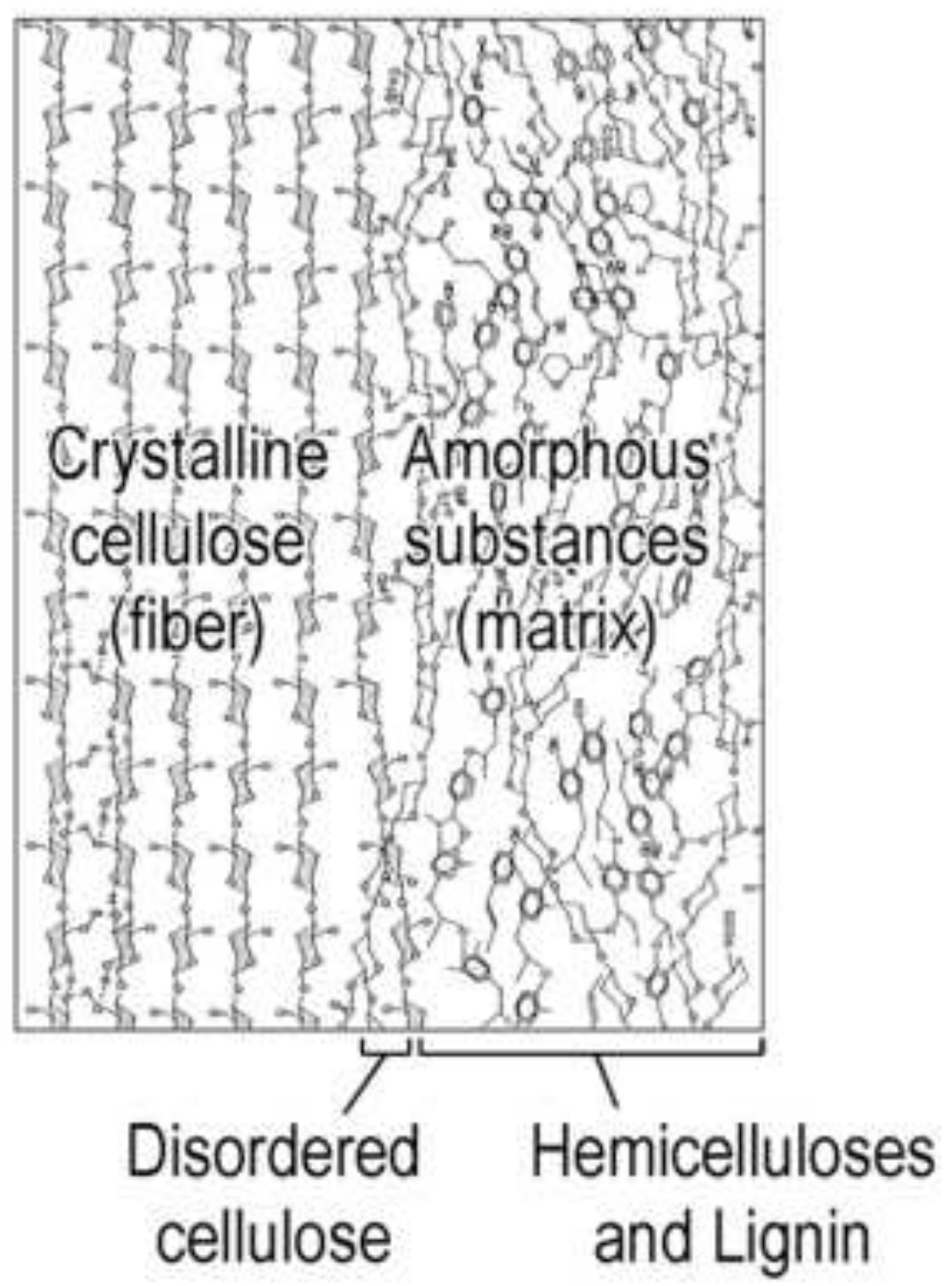
cellulose and Lignin 
Click here to download high resolution image

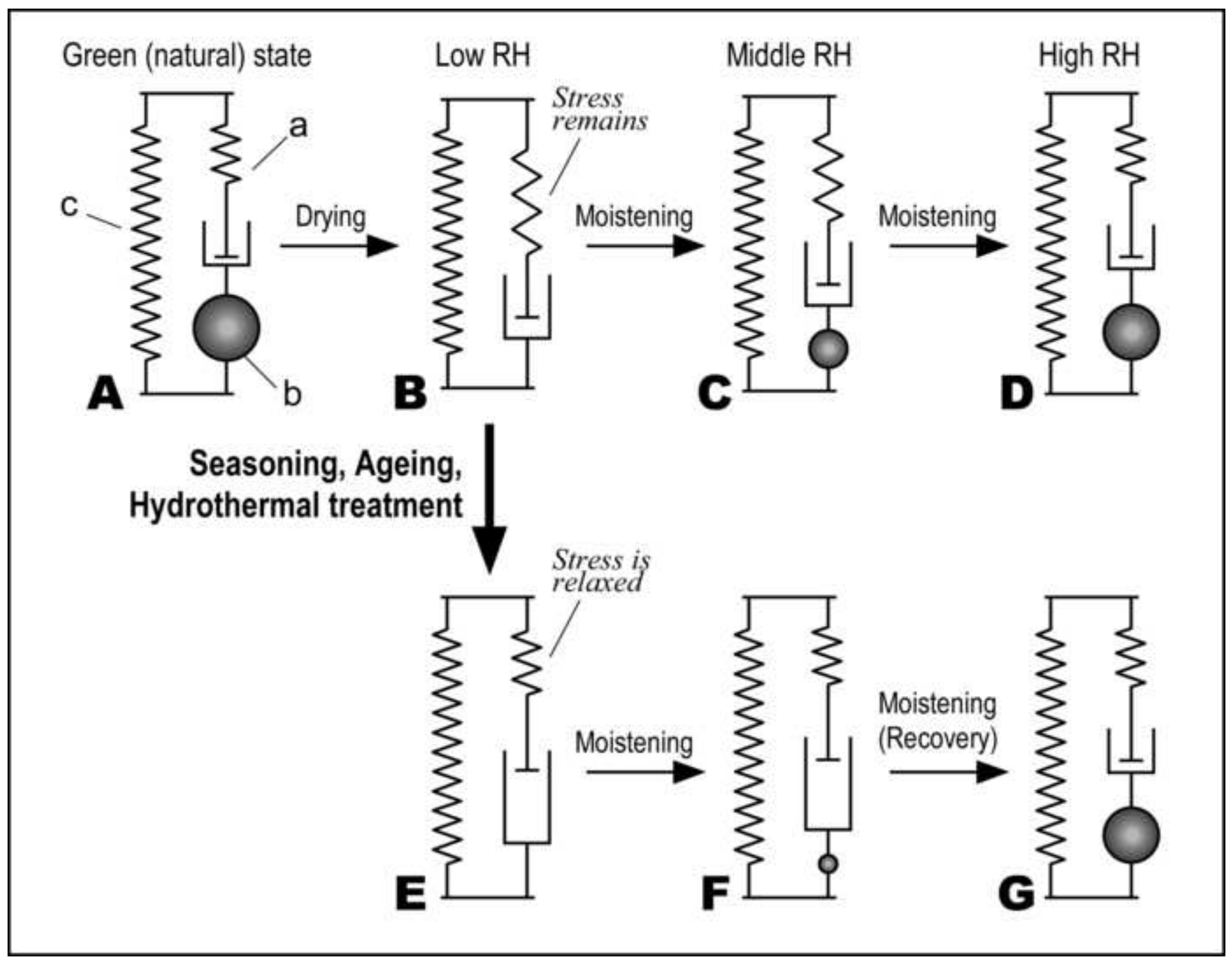




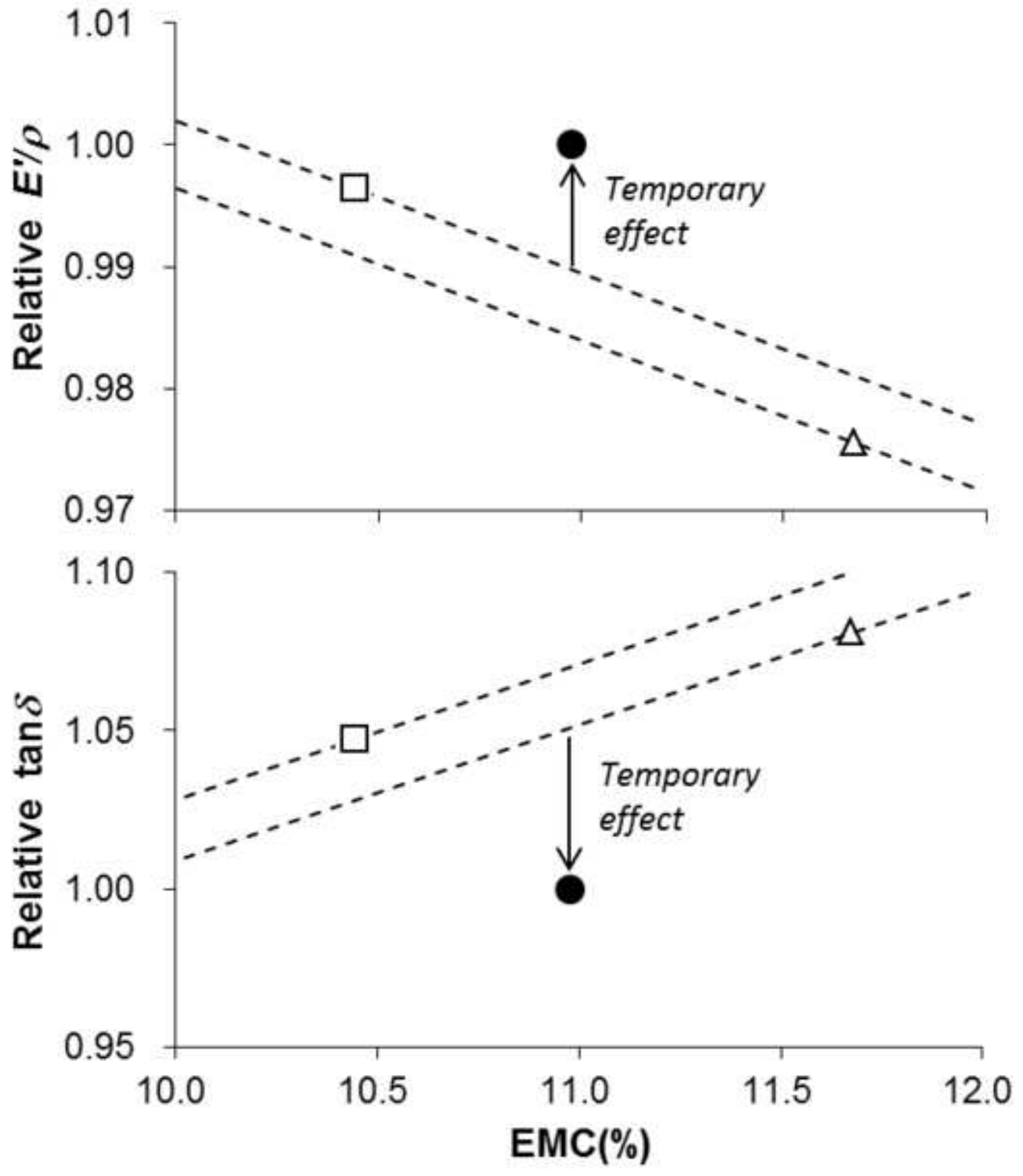




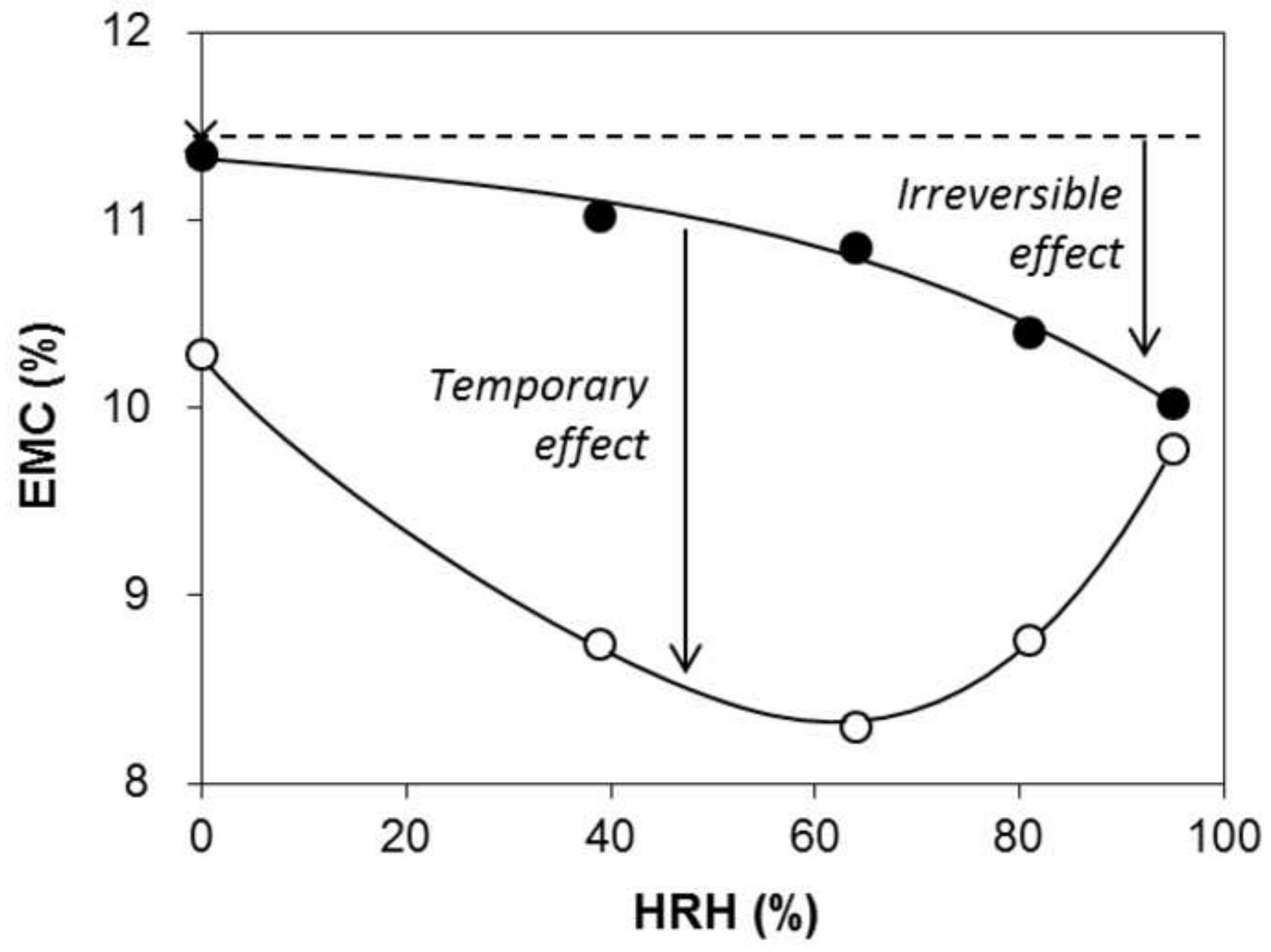



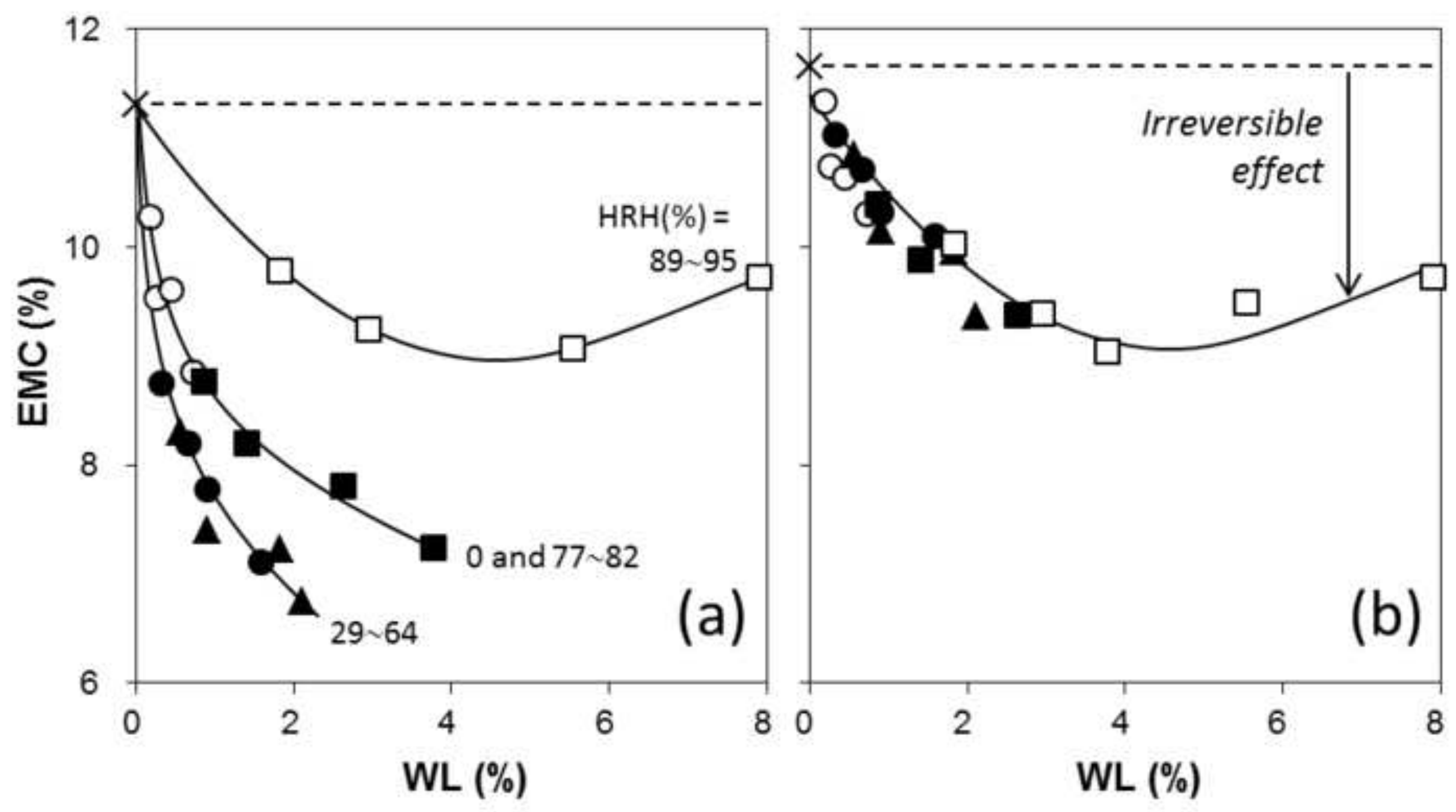


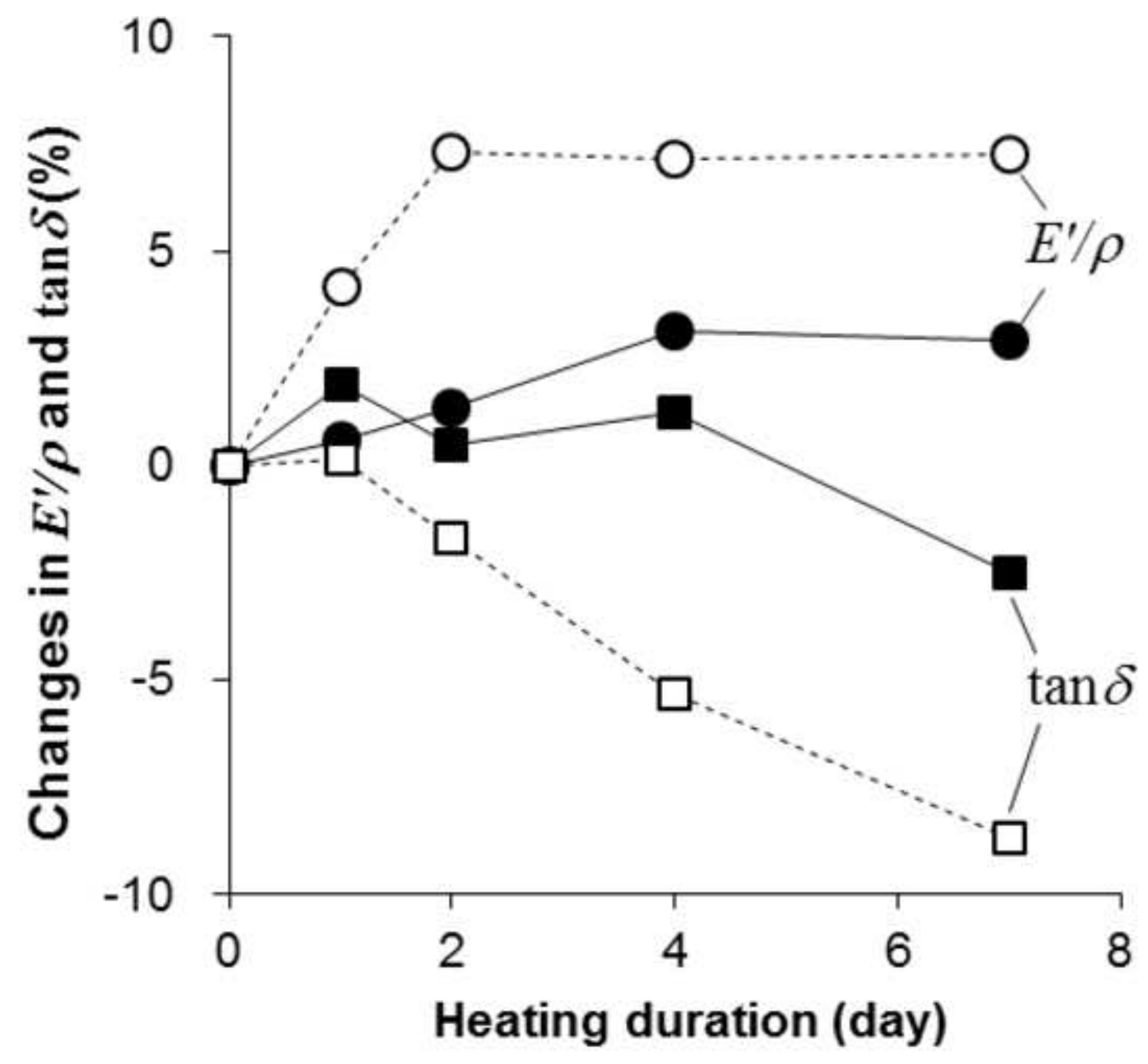

Click here to download high resolution image 

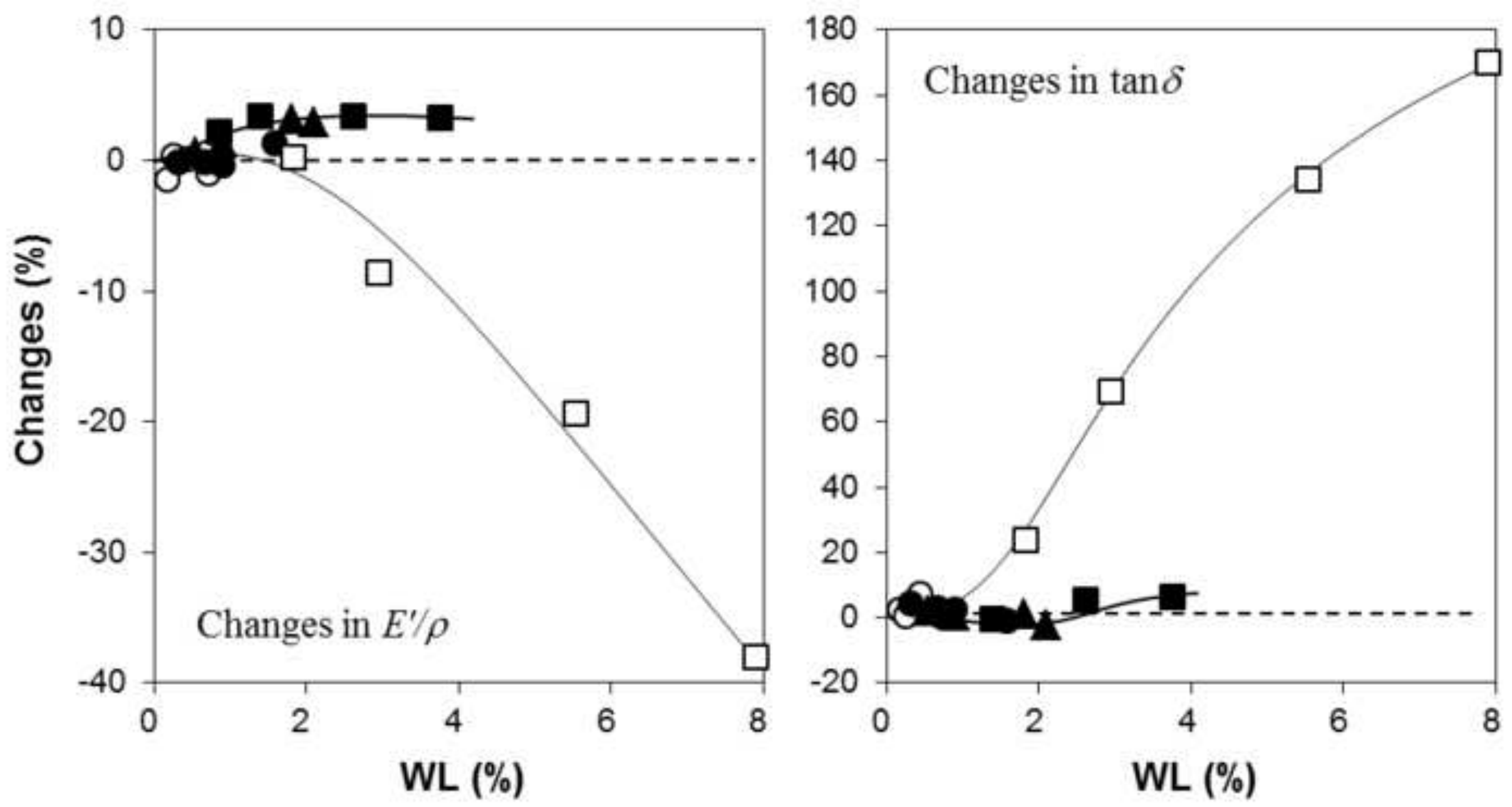


\section{For Reviewer \#1}

Thank you for your suggestions. Unfortunately I could not find articles you have suggested. I understand that wood properties vary widely even in a species, but I believe that the results presented in this manuscript are sufficiently reliable respect to their reproducibility. In this manuscript, I just want to suggest that the reversible changes should be considered when we discuss the effects of ageing and hydrothermal treatment.

For Reviewer \#2

Thank you for your comments. I have added some illustrations (Figures 2 and 3) for clearer understanding of wood structure and drying stress. 